\title{
Risk Analysis of Earthquake Disasters in Shandong and Coastal Areas and Its Preliminary Strategies
}

\author{
Sen Qiao, Zengping Wen,Changlong Li,Zongchao Li, Qing Wu,Tiefei Li \\ Institute of Geophysics, China Earthquake Administration \\ Beijing, China \\ qiaosen@cea-igp.ac.cn \\ 步对策 \\ 乔森, 温增平, 李昌珑, 李宗超, 吴清, 李铁飞 \\ 中国地震局地球物理研究所 \\ 北京 100081 , 中国 \\ qiaosen@cea-igp.ac.cn
}

山东及沿海区域地震灾害风险分析及初

\begin{abstract}
Shandong and its coastal areas are located in the eastern part of the North China tectonic region, and their strong seismic activities are uneven. There have been devastating earthquakes such as the Tanlu earthquake, the Bohai earthquake, and the Heze earthquake in history. With the development of the economy and the dramatic increase in population density, the earthquake disaster risk in Shandong and coastal areas has become increasingly high. This paper focuses on the characteristics of earthquake hazard analysis and earthquake disaster risk in Shandong and coastal areas, introduces population density and GDP development level of Shandong area into the disaster carrier, and then obtains the spatial distribution of earthquake disater risk in Shandong province. At last, according to the characteristics of earthquake disaster risk in Shandong, some suggestions to reduce earthquake disaster risk are given.
\end{abstract}

Keywords-Earthquake Hazard Analysis; Earthquake Disaster Risk Analysis; Disaster carrier; Shandong and its coastal areas; preliminary strategies

摘要：山东及其沿海地区位于华北构造区东 部, 其强震活动具有不均匀性。历史上发生
过郯庐大地震、渤海地震、菏泽大地震等破 坏性地震, 随着经济的发展和人口密度的剧 增, 山东及沿海地区的地震灾害风险逐渐增 高, 本文重点研究了山东及沿海区域的地震 危险性以及地震灾害风险的特征, 将山东地 区的人口密度及 GDP 发展水平等因素引入到 灾害的承载体中, 进而得到了山东地区的地 震灾害风险的空间分布情况。最后根据山东 地区的地震灾害风险特征, 给出了减轻地震 灾害风险的若干建议。

关键词:地震危险性分析, 地震灾害风 险分析, 灾害承灾体, 山东及沿海区域, 初 步对策

\section{I. 引言}

山东及附近沿海区域地处我国华北地 震构造区, 区域内地震构造较为复杂, 区域 内分布有北北东向与北北西向地震断裂, 并 具有部分共轭断裂的特点。区域内存在有多 个活动块体, 而且变形具有各个特点。山东 半岛有 3000 多公里黄金海岸, 海洋资源丰 富, 山东省及环渤海经济带的GDP 占全国 GDP 的比重也非常高, 而且山东人口密度非常 大。山东省部分区域处在我国著名的郯庐地 震带上, 北北东向郯庐断裂斜贯山东。在该 区域历史上发生了 1668 年郯城 8.5 级地震、 1937 年的菏泽 7 级地震、1969 年渤海 7.4 
级地震等一系列重大破坏性地震, 对当地社 会造成了重大的生命财产损失, 给当地经济 社会的发展造成了重大影响。近几十年内中 国的东部沿海地区未发生过破坏性大地震, 但是社会财富和人口密度却在急剧的增加, 因此山东及沿海区域将来要面对的地震灾 害风险越来越大。由于山东及沿海地区特殊 的区位优势, 在国家 “一带一路” 战略和海 洋强国战略中具有重要位置。因此, 对山东 及沿海区域开展地震危险性分析及地震灾 害风险分析具有重要的科学及社会意义。
II. 山东及沿海区域地震构造背景与地震 活动

山东境内主要的断裂带是欵庐断裂带 （图 1），该断裂带是是我国东部大陆地区 一条强烈地震活动带。1 668 年山东郯城 8.5 级地震、1969 年渤海 7.4 级地震、1975 年海 城 7.2 级地震就发生在这个地震带上。据记 载, 本带共发生 4.7 级以上地震 60 余次。其 中, 7-7.9 级地震 6 次;8 级以上地震 1 次。自 1400 年以来, 山东及沿海地区的地震活动性 越来越频繁，破坏性地震逐渐增多（图 2)。

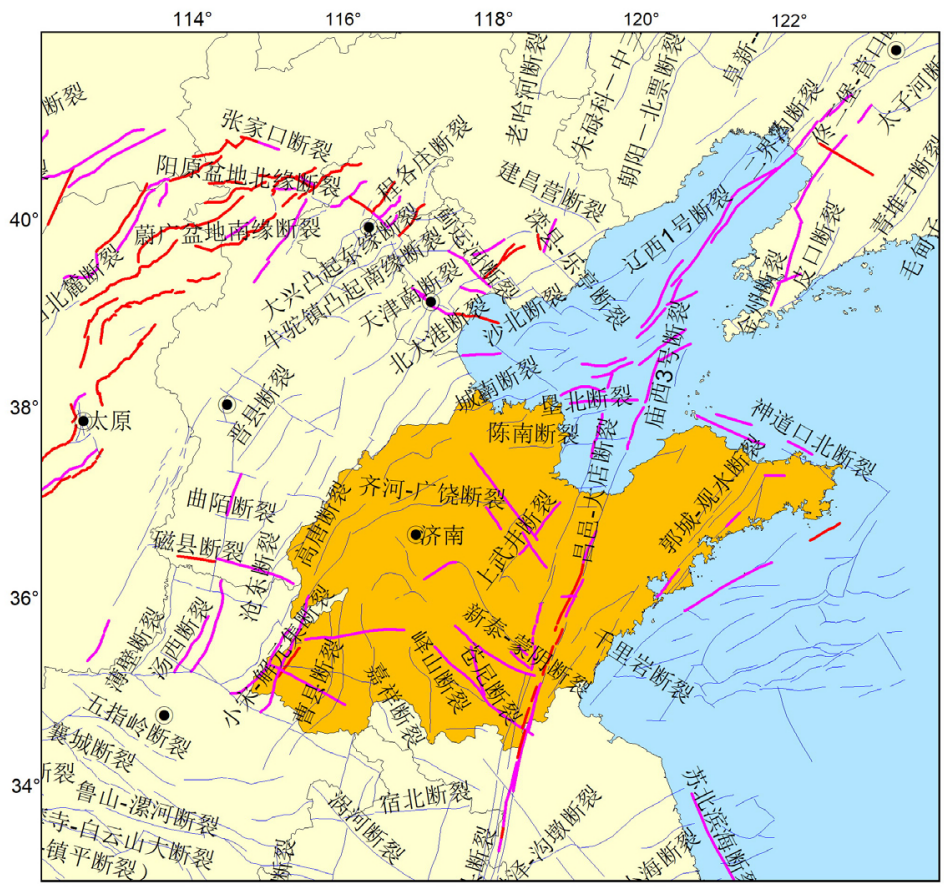

图 1 山东及沿海地区地震构造背景（吴清，2019）
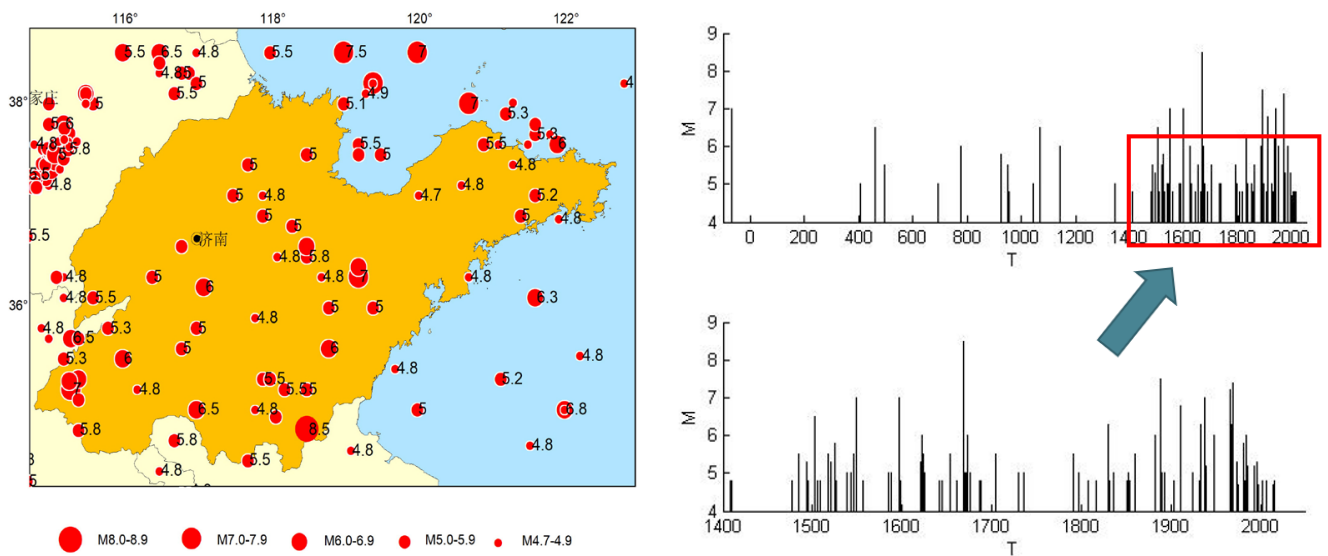

图 2 山东及沿海地区地震活动性 (吴清, 2019)

III.山东地区地震危险性分析

3.1 山东地区地震带的划分
第五代《中国地震动参数区划图》（GB 18306-2015) 采用了新的地震区带划分方法, 
首次采用三级潜在震源区划分，在全国划分 了 29 个地震带。其中华北平原地震带、淡 庐地震带、南黄海地震带位于山东省。在地 震带中划分地震构造区, 在山东及周边地区
共划分了 8 个地震构造区, 分别是华北平原 中部、华北平原北部、鲁西、胶东、南黄海、 渤海、辽西和辽东, 如图 3 所示。

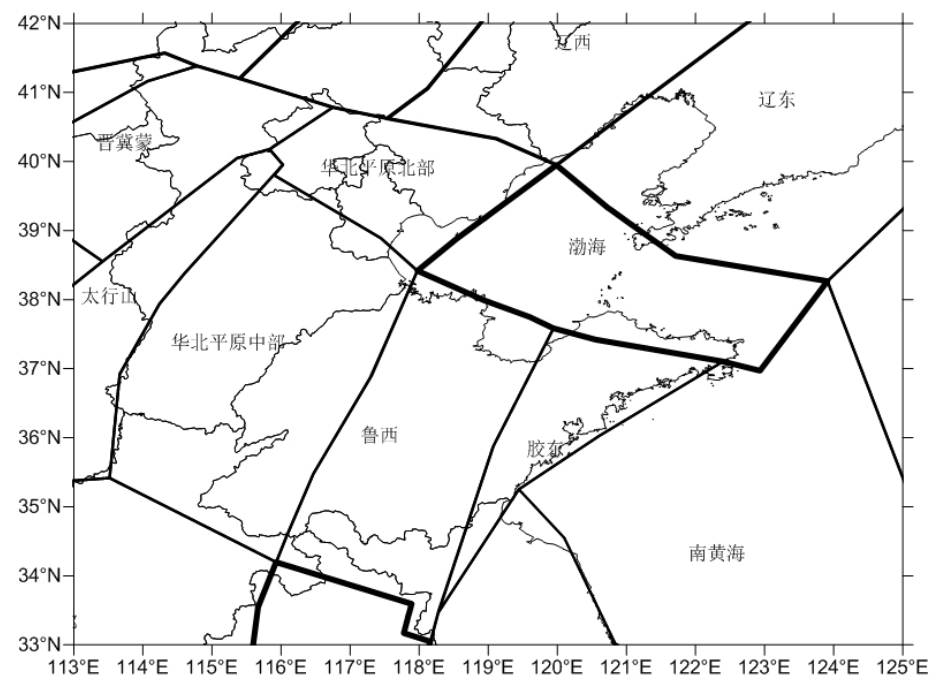

图 3 山东地震构造区划分

3.2 山东地区潜在震源确定

周本刚等（2013）通过对中国及邻区地震活 动特征的深入分析, 提出了潜在震源区三级 划分的方案。首先划分出作为地震活动性参 数统计单元的地震带, 在此统计单元内地震 震级频度关系符合 G-R 关系 (Gutenberg and Richter, 1944）; 再在地震区带内划分出不同 背景地震活动特征的地震构造区 (背景性地 震活动潜在震源区, SBG）; 然后在地震构 造区内围绕地震活动构造划分潜在震源区

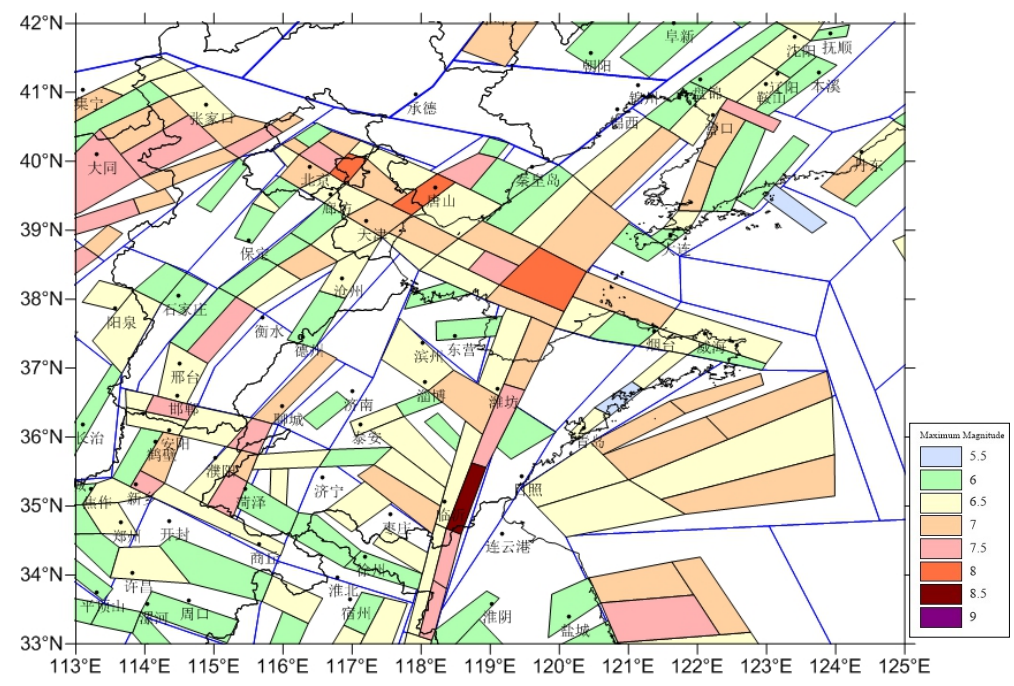

图 4 山东地区潜在震源确定

3.3 山东地区地震带、潜在震源地震活动性 参数确定
（构造性地震活动潜在震源区, SST）。潜在 震源区三级划分方法是本次潜在震源区划 分中最为突出的特色。在全国划分出 29 个 地震带, 77 个地震构造区 (SBG) 和约 1200 个潜在震源区 (SST)。山东的潜在震源区划 分如图 4 所示。需要注意的是, 在这套潜在 震源区划分方案中，潜在震源区是潜在地震 宏观震中（macro-epicenter）在地表的水平 投影区域。 
及东部中强地震区在地震构造划分、潜在震 源区划分方法与依据的侧重点有所差异。在 西部地区重视不同级别活动块体边界对大 地震活动的控制作用 (周本刚等, 2013) , 建立了不同类型发震构造模型, 并在发震构 造模型框架下充分运用构造类比原则, 力求 划分出潜在的新区和不低估高震级潜在震 源区的发震能力; 在东部地区加强中强地震
构造带的判识, 充实中强地震潜在震源区划 分的依据。

3.4 山东地区地震危险性分析结果 山东地区 50 年超越概率 10\%的峰值加速度 (PGA) 分布图如图 5 所示。由图 5 可见, 山东西部和中部地震危险性较高, 东部地震 危险性较低。

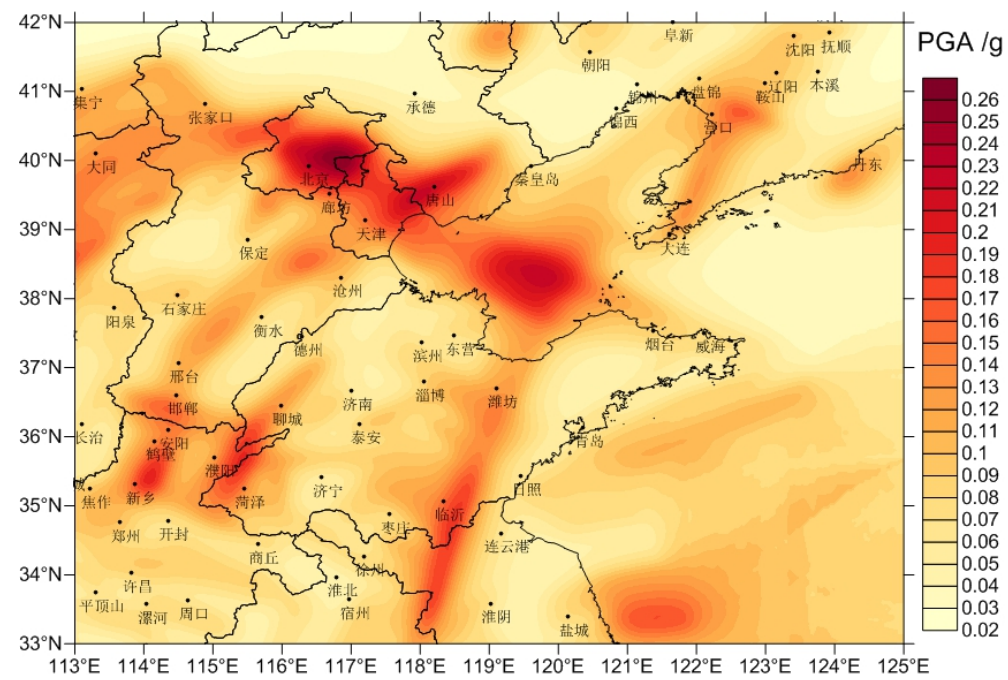

图 5 山东地区地震动峰值加速度分布图

IV.山东地震灾害风险分析

在山东地震危险性分析的基础上, 考虑 山东各县的人口、GDP 暴露情况, 计算出山 东各县的地震灾害风险。计算中使用地震动 峰值加速度（50 年超越概率 $10 \%$ ） ×人口因 子 $\times$ GDP 因子作为潜在地震风险因子, 此因 子的单位为万人 $\cdot$ 亿元 $\cdot g$ 。将计算结果分为 4 个等级：极高风险、高风险、中等风险和低
风险。风险因子小于 200 考虑为低风险; 200-1000 之间考虑为中等风险；1000-8000 之间考虑为高风险; 大于 8000 考虑为极高 风险。绘出的山东各县的地震灾害风险图如 图 6 所示。地震灾害风险等级为极高和高的 县市如表 1 所示。这里还需指出, 由于资料 的有限, 本文的暴露度数据未考虑人口和 GDP 的易损性和脆弱性。

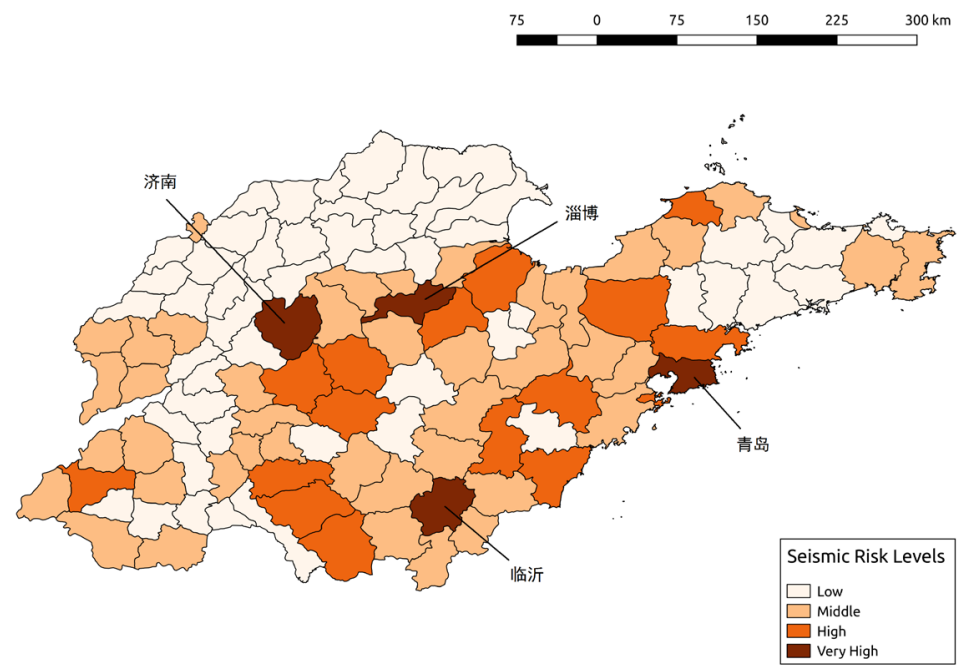

图 6 山东地震灾害风险图 
表 1 山东地震灾害风险为极高和高的县市

\begin{tabular}{cccccc}
\hline 排名 & 地名 & 风险等级 & 排名 & 地名 & 风险等级 \\
\hline 1 & 济南市区 & 极高 & 11 & 日照 & 高 \\
2 & 青岛市区 & 极高 & 12 & 即墨 & 高 \\
3 & 临沂市区 & 极高 & 13 & 寿光 & 高 \\
4 & 淄博市区 & 极高 & 14 & 诸城 & 高 \\
5 & 黄岛 & 高 & 15 & 龙口 & 高 \\
6 & 麥庄 & 高 & 16 & 邹城 & 高 \\
7 & 滕州 & 高 & 17 & 青州 & 高 \\
8 & 泰安 & 高 & 18 & 菏泽 & 高 \\
9 & 新泰 & 高 & 19 & 平度 & 高 \\
10 & 莱芜 & 高 & 20 & 莒县 & 高 \\
\hline
\end{tabular}

由图 6 和表 1 可看出, 济南、青岛、 临沂和淄博市区是山东地震灾害风险最高 的地区。

\section{V. 减轻地震灾害风险的初步对策和建议} 针对山东及沿海区域的地震构造背景、 地震活动性特征以及对山东省地震危险性 和地震灾害风险的分析结果, 本文对山东及 沿海区域减轻地震灾害风险提出初步对策 和建议:

（1）要加强对海陆联合地震观测与地 球物理观测。对这一区域的地震台网、地磁 台网、GPS 台网等要进一步优化布局, 适当 加密观测台站。对海域要加强建设海洋观测 台网。进一步加强对陆地和海域的地震活断 层探测。深入开展对地震灾害风险源的监测 与探测。

（2）要深入做好震害防御工作。所有 的工程项目, 在山东半岛陆地和海域要严格 按照《中国地震动参数区划图》( GB 18306－2015）设防; 对老旧房屋要开展抗震 加固; 对在山东建设的国家级重大工程、省 级重大工程要认真开展地震安全性评价与 地震灾害风险评估。

（3）要深入做好地震应急响应的准备 工作。要制定和完善省、市、县地震应急响 应预案，制定和完善各类企业的地震应急响 应预案, 并按照预案认真组织开展应急演练
工作。

（4）加强对地震灾害保险的研究与推 广应用。

（5）加强对防震减灾与减轻地震灾害 风险的科普宣传与教育。

（6）要严格依法行政。要对贯彻《中 华人民共和国防震减灾法》、地方法规等定 期开展执法检查，严肃查处违法违规的情 况, 确保国家的防震减灾重大决策得到贯彻 落实，确保人民生命财产的安全。

VI. 结论与讨论

通过上述分析, 可获得几点认识: 山东 的中部和西部地震危险性较高, 东部的地震 危险性相对较低; 临沂、淄博、青岛、济南 市区是山东地震灾害风险最高的地区; 要加 强对山东及附近海域的海陆联合地震观测 与地球物理观测, 加强对地震灾害风险源的 监测与探测; 要深入做好震害防御工作, 严 格按照《中国地震动参数区划图》(GB 18306 -2015）设防；认真组织开展地震应急响应 准备工作; 加强对地震灾害保险的推广应 用; 加强防震减灾科普宣传; 要严格依法行 政, 加强执法检查。

\section{致谢}

该项研究工作得到了国家重点研发计 划（2017YEC1500405）以及中国地震局地球 
物理研究所基本科研业务费专项 (DQJB19B06, DQJB19A0131, DQJB19A0133) 的联合资助

\section{参考文献}

[1] 中华人民共和国国家质量监督检验检疫总 局, 中国国家标准化管理委员会. 2015. 中国 地震动参数区划图. GB 18306-2015.
[2] 周本刚, 陈国星, 高战武, 等. 2013. 新地震 区划图潜在震源区划分的主要技术特色. 震 灾防御技术，8(2): 113-124.

[3]B. Gutenberg and C. F. Richter, "Frequenc $\mathrm{y}$ of earthquakes in California," Bulletin of th e Seismological Society of America, vol. 34, pp. 185-188, 1944. 